\title{
Educação para o trabalho: Desenvolvimento de competências não formais nos cursos vocacionais
}

\author{
Catarina Henriques*, Catarina Calado*, Paula Batista*, Ana Nunes*, Alcino Silva**, Henrique Mendes-dos-Santos*** \\ * Obra de Promoção Social do Distrito de Coimbra / CLDS+ Coimbra Concelho Solidário e Saudável, ** Câmara Municipal de \\ Coimbra - Divisão de Educação e Ação Social/ CLDS+ Coimbra Concelho Solidário e Saudável, *** Obra de Promoção Social do \\ Distrito de Coimbra
}

\begin{abstract}
Resumo
O presente artigo pretende apresentar o projeto Educação para o Trabalho, desenvolvido pela equipa do Contrato Local de Desenvolvimento Social Mais - CLDS+ Coimbra Concelho Solidário e Saudável, estruturado com o objetivo de estimular, de uma forma dinâmica e interativa, competências proactivas e pró laborais, junto de 43 jovens a frequentar os cursos vocacionais. De forma a melhor apresentar o referido projeto, iniciamos o presente trabalho com uma síntese da fundamentação teórica sobre o tema, seguida dos objetivos gerais do programa, da sua estrutura e da avaliação da sua eficácia. Terminamos o presente artigo com uma breve reflexão/conclusão sobre a sua implementação.
\end{abstract}

Palavras chave: Orientação Vocacional, Escola, Psicoeducação, Treino de Competências, CLDS+ Coimbra.

\begin{abstract}
This article aims to present Educação para o Trabalho, a project developed by Contrato Local de Desenvolvimento Social Mais - CLDS+ Coimbra Concelho Solidário e Saudável, in order to stimulate dynamic, interactive and proactive skills, in 43 young students from vocational classes. We started this work with a synthesis of theoretical information, followed by the objectives, the structure and the assessment of their effectiveness. This article ended with a brief reflection / conclusion of its implementation.

Keywords: Vocacional Counseling, School, Psychoeducation, Training Skills, CLDS + Coimbra.
\end{abstract}

\section{Introdução}

Num contexto académico e profissional em constante mutação, pautado por conceitos de crise, de absentismo escolar e de escassez de empregabilidade, torna-se premente refletir sobre o itinerário vocacional dos jovens desde tenra idade, com o intuito de aumentar a motivação e a responsabilização dos vários alunos pelo seu percurso académico e de diminuir os níveis de abandono escolar precoce e as situações de indisciplina. Para Teixeira (2010) a importância de trabalhar o processo de escolha e a capacidade de tomada de decisão precocemente, através da estimulação do conhecimento individual sobre aptidões, valores e interesses, assume um papel fundamental no desenvolvimento das competências sociais e emocionais necessárias para lidar com os desafios atuais.

A exploração vocacional tem sido um conceito amplamente estudado entre adolescentes e jovens adultos (Silva, 2010) dado a importância do conhecimento individual para a construção do itinerário de vida e para o compromisso com o percurso educativo. Com base no processo de exploração é possível que os jovens desenvolvam as suas capacidades, promovam comportamentos adaptativos e, consequentemente potenciem a sua competência social desde tenra idade (Gresham \& Elliott, 1987). Paralelamente as habilidades sociais deve ser igualmente exploradas do âmbito da implementação dos programas de intervenção terapêutica e educacional (Bandeira, Del Prette, Del Prette \& Magalhães, 2009) uma vez que são consideradas como fator de proteção e implicam diversos comportamentos que são necessários a uma relação interpessoal de sucesso (Murta, 2005).

Neste âmbito, o projeto Educação para o Trabalho, desenvolvido pela equipa do Contrato Local de Desenvolvimento Social Mais - CLDS+ Coimbra Concelho Solidário e Saudável, foi estruturado com o intuito de estimular, de uma forma dinâmica e interativa, competências proactivas e pró laborais, nomeadamente competências intrapessoais (autoconhecimento, autoestima, autocontrolo e gestão da frustração); competências interpessoais (comunicação, assertividade, resolução de problemas e resolução de conflitos); competências vocacionais (gostos, interesses, valores, maturidade e conhecimento do sistema educativo português e do mundo de trabalho) e hábitos de vida saudáveis (desporto, alimentação, sono, consumos e rotinas) (Gresham \& Elliott, 1990). Este projeto decorreu de Janeiro a Junho de 2015, num total de 40 sessões (com duração de 4 horas cada), dinamizadas em contexto escola (numa sala reservada para o efeito) e em espaços exteriores (de acordo com as temáticas a abordar). Importa referir que a equipa responsável do CLDS+ Coimbra conta com a Obra de Promoção Social do Distrito de Coimbra como entidade coordenadora e com a Câmara Municipal de Coimbra como entidade promotora das suas atividades. O plano de ação está delineado em três eixos, por forma a: (1) minimizar e combater a pobreza infantil, o isolamento e a exclusão social; (2) combater o absentismo; (3) criar redes de apoio/trabalho; e (4) dotar de competência - sociais, domésticas, empreendedoras -, através do desenvolvimento de ações de cariz social, educativo, cultural, desportivo e recreativo. O presente projeto integra os objetivos de atuação do CLDS+ Coimbra e surgiu no seguimento das dificuldades apresentadas na gestão comportamental de alguns alunos dos cursos vocacionais de cozinha e mesa bar na escola-sede, pelo 
Agrupamento de Escolas Coimbra Centro, com o intuito de minimizá-los.

\section{Objetivos}

O Projeto Educação para o Trabalho surge no seguimento das dificuldades apresentadas na gestão comportamental de alguns alunos dos cursos vocacionais de cozinha e mesa bar na escola-sede, pelo Agrupamento de Escolas Coimbra Centro com o objetivo de trabalhar competências pro sociais, académicas e vocacionais junto dos alunos do $1^{\circ}$ ano do Curso Vocacional de Cozinha e do Curso Vocacional de Mesa/Bar.

Para ir de encontro ao objetivo inicialmente traçado, este projeto tem o intuito de:

1) Explorar o Mercado de Trabalho, nomeadamente:

- Visitar espaços de diversas áreas de formação,

- Conhecer o funcionamento do mundo de trabalho (regras, valores, princípios) e,

- Experimentar tarefas de forma controlada (jobshadowing).

2) Co-responsabilizar os alunos pelo seu percurso de formação, procurando:

- Refletir sobre a importância da escola para a concretização dos objetivos futuros,

- Analisar os objetivos a curto, médio e longo prazo e,

- Explorar as consequências de determinadas ações vocacionais.

3) Estimular competências pessoais e sociais com o intuito de:

- Estimular a resistência à frustração;

- Desenvolver comportamentos assertivos em contextos sala de aula e,

- Trabalhar estereótipos e preconceitos.

\section{Método}

Os métodos de ensino utilizados no decorrer da aplicação do presente projeto agrupam-se em métodos ativos, métodos demonstrativos, métodos expositivos e métodos interrogativos. As metodologias ativas centram-se na construção do saber pelo educando, ou seja, pretende-se uma participação ativa e consciente, desempenhando o guia as funções de orientador pedagógico. Estes métodos assentam na premissa de que o educando é um agente ativo da sua própria aprendizagem. São métodos em que os educandos conduzem o processo de aprendizagem, a partir do seu ritmo e dos interesses, individuais e coletivos. No entanto, exige-se-lhes o desenvolvimento da criatividade, do pensamento crítico/reflexivo, da iniciativa, da descoberta e da responsabilidade.

Para além das metodologias supracitadas, considerámos pertinente, integrar a Aprendizagem Cooperativa (entreajuda dos participantes com vista a alcançar um objetivo pré-estabelecido).

Foram ainda utilizadas diversificadas técnicas, de acordo com as sessões previstas, nomeadamente, 1) pedagógicas (atividades Ice break, role-playing, brainstorming, estudos de caso, jogos, simulação, entre outras) e 2) psicoterapêuticas (Recurso a atividades de exploração, reflexão e interação pessoal).

\section{Participantes}

Este projeto foi desenvolvido para os alunos do $1 .^{\circ}$ Curso Vocacional de Cozinha e do 1. ${ }^{\circ}$ Curso Vocacional de Mesa e Bar. Destinou-se a quarenta e três alunos, tendo incidido, mais precisamente, num grupo de onze alunos.

\section{Procedimento}

O projeto Educação para o trabalho decorreu de janeiro a junho de 2015, num total de 40 sessões, com duração de 4 horas cada (aproximadamente). Estas foram realizadas quer em contexto escola (num espaço reservado para o efeito) quer em espaços exteriores (de acordo com as temáticas a trabalhadas e com a disponibilidade dos parceiros). Considerámos pertinente que, em algumas sessões (calendarizadas previamente), tivessem estado envolvidos todos os elementos da turma com vista a facilitar a participação dos alunos alvo nas dinâmicas da turma e a partilhar o trabalho realizado no decorrer do projeto.

A dinamização das sessões teve início no dia 8 de janeiro ( $5^{\text {a }}$ feira). $\mathrm{O}$ grupo inicial foi constituído por 10 jovens ( 5 de cada turma) que, embora motivados para participar nas sessões, apresentavam um comportamento pouco adequado às dinâmicas de sala e interesse reduzido nas atividades escolares. $\mathrm{O}$ projeto foi explicado aos jovens e foram estipuladas conjuntamente as regras de funcionamento.

Ao longo do projeto foram dinamizadas sessões em contexto sala de aula (ver fig.1) sobre diversas temáticas prementes à vida em sociedade, tais como sobre profissões; factos históricos, gestão de dinheiro (poupança e salário); droga; violência doméstica; empreendedorismo e doçaria conventual.

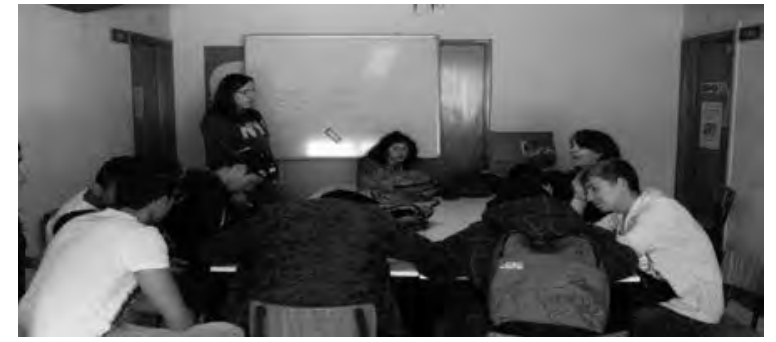

Fig. 1 sala onde decorreu o projeto - SPO

Paralelamente foram contactadas várias entidades com o intuito de articular visitas e atividades de job shadowing (ver fig.2, Fig.3, Fig.4).

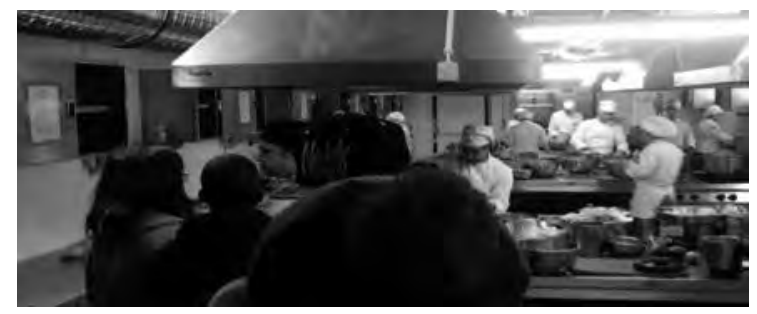

Fig. 2 Escola de Hotelaria e Turismo de Coimbra 


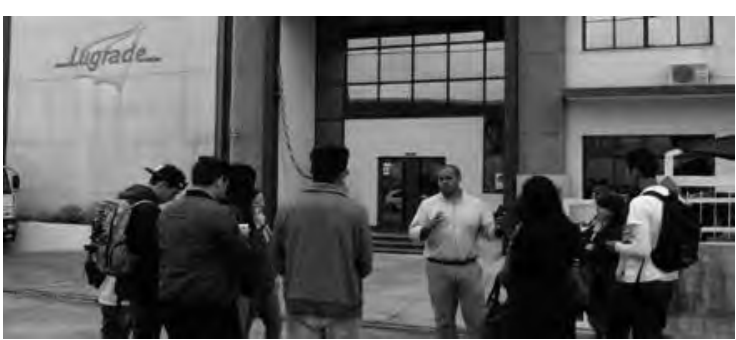

Fig. 3 Visita à fabrica de bacalhau Lugrado

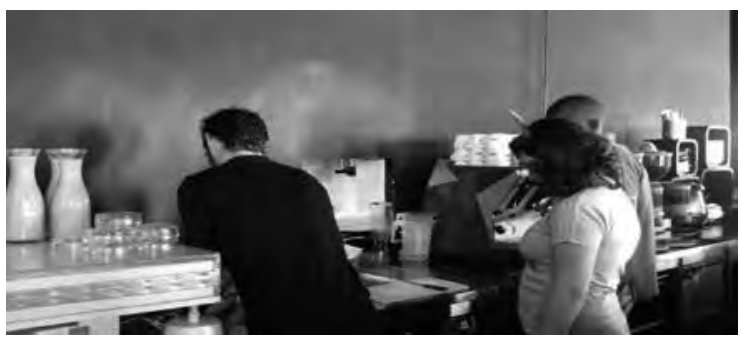

Fig. 4 Cafetaria do Museu da Ciência

A concretização do referido projeto contou ainda com sessões históricas (ver fig.5) e com momentos desportivos (ver fig.6 e fig.7).

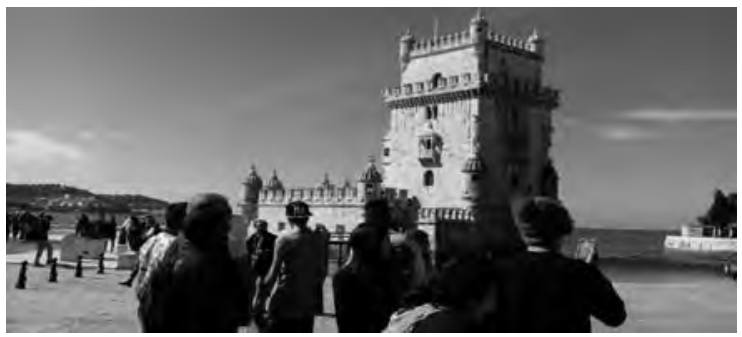

Fig. 5 Torre de Belém

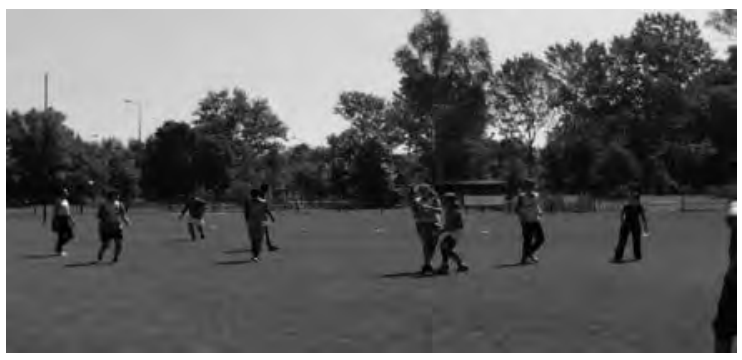

Fig. 6 Escola Superior Agrária de Coimbra

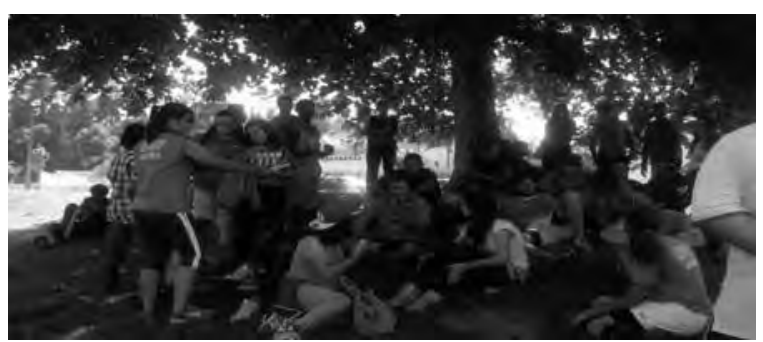

Fig. 7 Sessão de Encerramento: peddy-paper

A sessão final do projeto foi ainda noticia em dois dos jornais da região, por ser considerada uma boa pratica (ver fig.8 e fig.9).
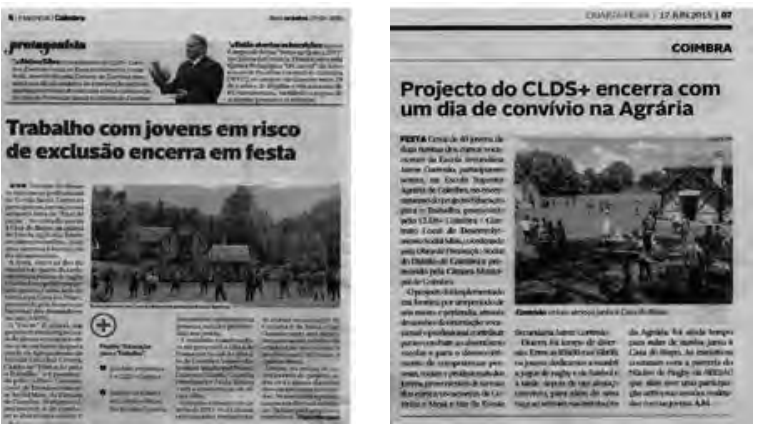

Fig. 8 e 9 Notícias relativa à Sessão de Encerramento do Projeto Educação para o Trabalho

\section{Resultados}

Do projeto, constaram vários momentos de avaliação e análise da eficiência e eficácia da intervenção, a fim de acompanhar os resultados da sua implementação (nos alunos sinalizados, nas respetivas turmas e nos seus Conselhos de Turma).

Primeiramente foi feita uma avaliação inicial que englobou a descrição dos alunos pela equipa docente e uma análise qualitativa dos comportamentos e expetativas dos alunos face ao projeto pela equipa do CLDS+. A implementação do projeto foi acompanhada por sessões de trabalho cooperativo com Conselho de Turma, com o intuito de analisar a resposta dos alunos aos conteúdos trabalhados e o seu processo de evolução. No término do projeto foi realizada uma avaliação final na qual os professores analisaram a evolução da resposta dos alunos aos propósitos do projeto e refletiram sobre as mudanças despoletadas pelo mesmo. $\mathrm{Na}$ opinião do corpo docente este projeto foi uma mais-valia uma vez que permitiu "a retirada dos alunos mais problemáticos das salas de aulas possibilitando um melhor funcionamento das mesmas; o alargamento de algumas atividades aos restantes alunos das turmas e a ligeira evolução na aquisição e aplicação de competências sociais por parte de alguns alunos.” Os professores reforçaram ainda que "a boa comunicação e articulação entre diretores de turma, conselho de turma, SPO, técnicos do CLDS+ e direção da escola" foi um contributo fundamental para o decorrer da intervenção.

A avaliação final realizada junto dos alunos teve o intuito de analisar qualitativamente as aprendizagens não formais adquiridas e o grau de satisfação face às atividades realizadas. Procurou ainda consciencializar os jovens para a importância de refletirem sobre o seu itinerário vocacional e responsabilizarem pelo seu percurso académico. Na sua ótica este projeto

Para a equipa do CLDS+, consideramos que, na generalidade, os alunos se foram tornando mais assíduos e pontuais, mais atentos e interessados pelas diversas temáticas abordadas e começaram a integrar a noção de regras, limites e funcionamento de grupo em contexto de sessão.

De um modo geral todo projeto decorreu de forma satisfatória, tanto no trabalho desempenhado pela equipa organizadora como no grau de satisfação transmitido pelos professores e pelos jovens que participaram na atividade 


\section{Discussão e Conclusões}

O treino de competências pessoais, sociais e vocacionais revelou ser estratégia exploratória adequada e construtiva ao nível da promoção de comportamentos saudáveis e ajustados ao contexto escolar.

Desta forma, é importante que este tipo de intervenção possa ser implementada e generalizada junto de jovens em contexto desfavorecido, em risco de abandono escolar ou em situações de incerteza vocacional cristalizada no sentido de treinar comportamentos pro sociais, de melhorar o conhecimento sobre o mundo do trabalho e das profissões e de responsabilizar os jovens pelos seus itinerários vocacionais atempadamente.

Da revisão bibliográfica realizada, podemos também concluir que este tipo de sessões aliada às atividades escolares desde os primeiros anos do ensino básico pode diminuir os comportamentos de indisciplina, reduzir os níveis de absentismo e, consequentemente, traduzir-se numa maior envolvência dos alunos nas atividades escolares e numa melhor qualidade do ensino. De acordo com Ferrandiz, Bermejo, Fernández, Sainz, Valverde e Araújo (2014), a aplicação de programas, enquanto atividades preventivas ou remediativas, teoricamente fundamentadas e planificadas de modo sistemático, deve ir de encontro às necessidades detetadas dum determinado contexto educativo. Gresham e colaboradores (2001) acrescentam que é fundamental desenvolver/promover treinos de competências sociais em grupos específicos, como por exemplo, estudantes com dificuldades no funcionamento cognitivo, académico, emocional e comportamental para melhorar o funcionamento do sistema educativo.

Sintetizando, os programas de intervenção preventiva e de exploração vocacional com adolescentes, em contexto escolar, podem ser considerados uma mais-valia na estimulação de comportamentos pró sociais, na diminuição de comportamentos de risco e no decréscimo dos níveis de abandono escolar.

\section{Referencias}

Bandeira, M., Del Prette, Z., Del Prette, A., \& Magalhaes, T. (2009). Validacao das escalas de habilidades sociais, comportamentos problematicos e competencia academica (SSRS-BR) para o ensino fundamental. Psicologia:Teoria e Pesquisa, 25 (2), 271-282.

Ferrándiz, C., Bermejo, R., Fernández, M. S., Valverde, J. \&Araújo, A. (2014). Inteligência Emocional: Aplicações e Implicações Educativas. In Almeida, L. \& Araújo, A. (1 $\left.{ }^{a} E d\right)$, Aprendizagem e sucesso escolar: Variáveis pessoais dos alunos (pp.137-171). Braga: ADIPSIEDUC.

Gresham, F., \& Elliott, S. (1987). The relationship between adaptive behavior and social skills: issues in definition and assessment. The Journal of Special Education, 21 (1), 167-181.

Gresham, F., \& Elliott, S. (1990). Social Skills Rating System Manual. Circle Pines, Minnesota, EUA: American Guidance Service.

Gresham, F., Sugai, G., \& Horner, R. (2001). Interpreting outcomes of social skills training for students with high-incidence disabilities. Exceptional Children, 67 (3), 331-344.

Murta, S. (2006). Programas de prevenção a problemas emocionais e comportamentais em crianças e adolescentes: Lições de três décadas de pesquisa. Psicologia, Reflexão e Crítica, 20(1), pp.1-8.

Silva, M. J. (2010). A inteligência emocional como factor determinante nas relações interpessoais: Emoções, Expressões Corporais e Tomadas de Decisão. Dissertação de mestrado. Universidade Aberta de Lisboa.

Teixeira, M. (2010). Estudo sobre a eficácia de um programa de inteligência emocional no auto-conceito de alunos do $2^{\circ}$ ciclo do ensino básico. Dissertação de mestrado. Universidade Fernando Pessoa: Porto. 